Alurch vergleichende Versuche festgestellt, daß das Jodmethylat des 1Phenyl-5-methyl-pyrazols in Alkohol erheblich viel schwerer löslich ist, als das des isomeren 1-Phenyl-3-methyl-pyrazols, das sich schon in der Kälte leicht löst, sowie, daß das Chloroplatinat der trsteren Base leichter in Alkohol-Salzsäure löslich ist, als das der letzteren. So erklärt es sich, daß das Claisen-Roosensche Platinsalz rom Schmp. $149^{\circ}$ der Hauptmenge nach ans dem Platinat des 1-Phenyl-3-methyl-pyrazols besteht, während das Basengemenge, von dem dahei susgegangen wurde, sicher der Hauptmenge nach 1-Phenyl5 -methyl-pyrazol enthielt. Was das Jodäthylat betrifft, so schmilyt thas aus meinem reinen 1-Phenyl-5-methyl-pyrazol dargestellte bei $208^{\circ}$ unter Aufschäumen, genau entsprechend den Angaben von Claisen und Roosen, und gerade so, wie das zum Vergleich nit übersandte Priparat.

Rostock, in Januar 1907 .

76. R. Sto ermer: Berichtigung zu meiner Abhandlung über die Synthese von Aldehyden und Ketonen aus asymm. disubstituierten Äthylenglykolen und deren Äthern ${ }^{1}$ ).

[Mitteilung aus dem chemischen Institut der Universität Rostock.]

(Eingegangeu am. 24. Januar 1907.)

Ich hatte angegeben, daß beim Erhitzen von Phenoxy-ditolylathylen mit alkoholischem Kali anf $240^{\circ}$ neben der entsprechenden it thox verbinclung auch $\mathrm{Di}-p$-tolyl-äthylen, $\left(\mathrm{C}_{7} \mathrm{H}_{7}\right)_{2} \mathrm{C}: \mathrm{CH}_{2}$, entstehe, dis mein Mitarbeiter Hr. Sibbern-Sibbers als Öl vom Sdp. $186^{\circ}$ bei $20 \mathrm{~mm}$ Druck isoliert und außer durch die Analyse durch die ÜberFiihrung in Ditolylketon und dessen Oxim identifiziert hatte. Hr. Prof. Bistrzycki war so freundlich, mich darauf aufmerksam zu machen, dak dies früher als $O$ l beschriebene Äthylen von $\mathrm{ihm}^{2}$ ) fest erhalten worden sei und bei $61^{\circ}$ schmelze. Eine von mir sofort angestellte Nachprüfung des Sibbersschen Präparats ergab, da $B$ es beim Impfen mit einer mir freundlichst ron Hrn. Bistrzycki überlassenen Probe seines festen Jitolyläthylens zwar nicht erstarrte, wohl aber beim $A b-$ kühlen in einer Kältemischung. Die dabei gewonnenen Krystalle schmolzen, ans verdünntem Alkohol umkrystallisiert, bei $26-27^{\circ}$, die Wenge war "aber zu gering, um eine größere Anzahl von Krystallisationen damit vorzunehmen. Während das obige Produkt anf Per-

1) Diese Berichte 39, 2288 [1906]. 2) Diese Berichte 38, 840 [1905]. 
manganat sehr stark einwirkte, zeigten die erhaltenen Krystalle kaums. noch entfärbende Wirkung. Es liegt daher der Schluß nahe, daß hier Mischkrystalle von Ditolyl-äthylen mit Ditolyl-methan (Schmp. $22-23^{\circ}$ ) vorlagen. Die Zahlen für den Kohlenstoff- und Wasserstoffgehalt des Methanderivats, $\mathrm{C}=91.8$ und $\mathrm{H}=8.2$, liegen so dicht bei denen des Äthylenabkömmlings $\mathrm{C}=92.3$ und $\mathrm{H}=7.7$, daß ein Irrtum Sibbers, der $\mathrm{C}=92.19$ und $\mathrm{H}=7.98$ fand, wohl begreiflich erscheint. Das Ditolyläthan ist flüssig, kommt also nicht in Frage.

Die Angaben Bistrzyckis über das Ditolyläthylen sind also als die richtigen anzusehen.

Rostock, im Dezember 1906.

\section{Fmil Fischer:}

\section{Zur Kenntnis der Waldenschen Umkehrung.}

[Aus dem I. chemischen Institut der Universität Berlin.]

(Vorgetragen in der Sitzung vom Verfasser.)

Vor ungefähr 10 Jahren hat Hr. P. Walden unter dem 'litel „Über die gegenseitige Umwandlung optischer Antipoden« fünf $\mathrm{Al}$ handlungen ${ }^{1}$ ) veröffentlicht, in denen gezeigt wird, daß optisch-aktive Substanzen ohne den Umweg über die Racemkörper direkt in ihre Antipoden verwandelt werden können.

Diese Entdeckung war seit den grundlegenden Untersuchungen Pasteurs die überraschendste Beobachtung auf dem Gebiete der optisch-aktiven Substanzen. Wenn sie trotzdem seither kaum mehrGegenstand der Diskussion oder experimentellen Forschung gewesen. ist, so dürfte das wohl dem Eindruck zuzuschreiben sein, daß das Phänomen durch Walden eine erschöpfende Behandlung erfahren hat.

Seine Versuche erstrecken sich vorzugsweise auf die beiden aktiven Äpfelsäuren, die entsprechenden Halogenbernsteinsäuren und die eine aktive Asparaginsäure. Die wichtigsten Resultate hat Walden in folgendem Schema ${ }^{2}$ ) zusammengefaßt, in dem die Übergänge unter

1) Diese Berichte 29, 133 [1896]; 30, 2795 und 3146 [1897]; 32, 1833 und 1855 [1899].

2) Diese Berichte 30, 3151 [1897]. 